\title{
Accumulation of mutations in reverse transcriptase of hepatitis B virus is associated with liver disease severity in treatment-naïve Chinese patients with chronic hepatitis B
}

\author{
Bin Zhu ${ }^{A, E, F}$, Tianbao Wang ${ }^{B}$, Xiaoxia Wei ${ }^{B}$, Ya Zhuo ${ }^{C}$, Amin Liu' ${ }^{C}$, Guangwen Zhang ${ }^{D}$ \\ Infectious Disease Department of the First Affiliated Hospital of Xinxiang Medical University, Henan, China \\ A - research concept and design; $\mathrm{B}$ - collection and/or assembly of data; $\mathrm{C}$ - data analysis and interpretation; \\ $D$ - writing the article; $E$ - critical revision of the article; $F$ - final approval of article
}

\section{Address for correspondence \\ Bin Zhu}

E-mail:binzhu04@163.com

Funding sources

None declared

Conflict of interest

None declared

Received on February 7, 2016

Revised on April 3, 2016

Accepted on July 4, 2016

\begin{abstract}
Background. Mutations in reverse transcriptase (RT) of the hepatitis B virus (HBV) are demonstrated to be strongly associated with nucleos $(t)$ ide analog resistance, which is supposed to be the biggest obstacle during the long-term anti-viral treatment of chronic hepatitis B. However, the presence of RT mutations in treatment-naïve chronic hepatitis $B$ patients and its clinical significance are not well known.

Objectives. To investigate the significance of mutations in reverse transcriptase of the hepatitis $B$ virus in treatment-naiive Chinese patients with chronic hepatitis B.

Material and methods. In this study, 288 treatment-naiive chronic HBV patients were recruited and the $R T$ region was sequenced. The results showed that 71 patients (24.65\%) were found with RT mutations, within which there were no well-defined primary nucleotide analog-resistant mutations.

Results. There were a total of 28 mutant sites, which formed 3 dominant mutant clusters: rt124-139, rt191212 and rt225-229. Among these 71 patients, 63.38\% (45/71) of patients had a single mutation while $19.72 \%(14 / 71), 12.68 \%$ (9/71) and 4.23\% (3/71) of patients had 2, 3 or 4 mutations, respectively. Patients with RT mutations showed significantly decreased serum baseline HBV DNA loads $(p=0.0363)$ and blood platelet count $(p=0.0181)$ than patients without RT mutations. Patients with multiple mutant sites $(\geq 2)$ had significantly decreased baseline HBV DNA loads $(p=0.0004)$ and blood platelet count $(p=0.0011)$ than patients with single mutant site. Moreover, the number of RT mutant sites is significantly associated with severity of liver fibrosis $(p=0.0128)$.

Conclusions. This study demonstrated that there was a prevalence of RT mutations in treatment-naive chronic hepatitis B patients, which reflects a tougher liver environment for the virus and deeper liver injury for the host. Accumulation of RT mutations was associated with liver disease severity in treatment-naive chronic hepatitis $B$ patients.
\end{abstract}

Key words: hepatitis B virus, mutation, treatment-naiive, reverse transcriptase

DOI

10.17219/acem/63998

Copyright

Copyright by Author(s)

This is an article distributed under the terms of the

Creative Commons Attribution Non-Commercial License

(http://creativecommons.org/licenses/by-nc-nd/4.0/) 
Hepatitis B virus (HBV) infection is the most common etiologic agent of acute and chronic liver disease in China. ${ }^{1}$ Individuals infected with HBV in infancy or childhood often develop into chronic hepatitis, eventually progressing from liver fibrosis to cirrhosis or hepatocellular carcinoma. ${ }^{2} \mathrm{HBV}$ is an enveloped, partially doublestranded DNA virus containing a genome of 3200 nucleotides encoding four open reading frames (ORFs): pre-S/S, pre-C/C, HBX and polymerase. The polymerase gene includes four domains such as the terminal protein, spacer, ribonuclease $\mathrm{H}$ and reverse transcriptase (RT). The RT replicates the HBV genome through its DNA polymerase activity using RNA intermediates as a template. ${ }^{3}$ Because the RT does not possess proof reading activity during viral replication, the error rate of HBV genome synthesis has been mounted as $10^{-7}$ per nucleotide, which is 10 -fold higher than other DNA viruses. ${ }^{4}$ The high rate of HBV mutation results in lots of genomic variants and survival of the fittest during the selection of liver environment, anti-viral drugs and host immune defense.

Mutations in the RT region were thoroughly reported in recent data for their nucleos(t)ide analog-resistant activity. For instance, rtM204I is a classical mutation reducing susceptibility to monotherapy by lamivudine (LMV) or telbivudine (LdT); the rtI169T mutation was reported as an entecavir (ETV)-resistant amino acid substitution and rtA181V showed its resistance to adefovir dipivoxil (ADV). ${ }^{5-8}$ In addition, gene mutations A799G, A987G, and $\mathrm{T} 1055 \mathrm{~A}$ in the $\mathrm{RT}$ region have been reported consistently associated with hepatocellular carcinoma (HCC) and these mutations were always detectable $4-5$ years prior to $\mathrm{HCC}$ diagnosis. ${ }^{9}$ Moreover, since the envelope (S) gene is completely overlapped by the RT gene, mutations in the RT region may produce changes in its overlapping $S$ gene, causing amino acid substitution or stop codon in the $S$ protein. For instance, rtM204I and rtL180M/M204I produce I195M and W196S in the S protein, leading to an altered structural integrity of $S$ protein and consequently reduced its binding affinity to anti-HBs antibody. ${ }^{10}$

Compared with single amino acid mutation, a combination of 2 or more mutations is complicated and always linked to the development of HCC. A combination of G1613A + C1653T or any pre-S mutation + C1653T + T1753V significantly associates with hepatocellular carcinoma in genotype C HBV infected patients. ${ }^{11,12}$ Among the 8 key mutations comprising G1613A, C1653T, T1753V, A1762T, G1764A, A1846T, G1896A and G1899A in the $\mathrm{X} /$ preC region, a combination of $\geq 6$ mutations shows increased risk of $\mathrm{HCC}$ in genotype $\mathrm{C} 2 \mathrm{HBV}$ infected Korean patients. ${ }^{13}$ However, the combination of mutations in the RT region and its clinical significance have seldom been discussed.

In this study, we sequenced the RT gene of HBV in 288 treatment-naïve chronic hepatitis B patients and 71 patients $(24.65 \%)$ were found with RT mutations. The pattern of mutations and nucleotide analog-resistant muta- tions as well as the combination of these mutations were analyzed.

\section{Material and methods}

\section{Patients and blood samples}

A total of 288 treatment-naïve chronic HBV patients were enrolled at the First Affiliated Hospital of Xinxiang Medical University (Henan, China) from July 2009 to May 2014. All patients were diagnosed as chronic hepatitis B based on the criteria suggested by the Chinese Medical Association for Liver Diseases in 2005. ${ }^{14}$ The average duration time of $\mathrm{HBV}$ infection since first diagnosed as serum HBsAg positive was $28.71 \pm 10.24$ years. They were all confirmed LMV, ADV, ETV, LdT and interferon (IFN) treatment-naïve. Patients co-infected with the hepatitis $\mathrm{A} / \mathrm{C} / \mathrm{D}$ virus or human immunodeficiency virus, or other concomitant liver disease such as autoimmune liver disease, primary biliary cirrhosis, alcohol or drug abuse were excluded. All patients had written consent on entry into the trials and agreed to authorize the hospital to deal with their blood and tissue samples for research purposes. The study was approved by the Ethics Committee of the First Affiliated Hospital of Xinxiang Medical University. Patients' sera were collected and stored at $-80^{\circ} \mathrm{C}$.

\section{Diagnostic tests}

Liver function tests and serum HBV markers were conventionally conducted in the clinical lab of the First Affiliated Hospital of Xinxiang Medical University. Serum hepatitis B s antigen (HBsAg), anti-HBs, hepatitis B e antigen ( $\mathrm{HBeAg}$ ), anti-HBe and anti-HBc were determined on the wholly automatic immune fluorescence analyzer Abbott Type I2000 (Abbott Laboratories, USA) using the original, attached commercial kits. Serum alanine aminotransferase (ALT), aspartate aminotransferase (AST) and total bilirubin (TBIL) were assayed by the wholly automatic biochemical analyzer DXC800 (Beckman Coulter, USA). Blood platelet count was determined on the fully automatic hematology analyzer LH780 (Beckman Coulter, USA). Serum HBV DNA loads were quantified with fluorescence quantitative PCR assay (Da'An GENE, Guangzhou, China) performed on an ABI 7500 (Applied Biosystems, USA). The detection sensitivity was as low as 500 copies/mL.

\section{Amplification and sequencing of HBV RT region}

HBV DNA was extracted from $500 \mu \mathrm{L}$ sera of the patients according to the protocol of the QIAamp DNA Blood Kit (Qiagen, Germany). The HBV RT gene was amplified by nested PCR as previously described. ${ }^{15}$ 
The primers used for the outer round PCR system were 5-AGTCAGGAAGACAGCCTACTCC-3 (nt 3146-3167) and 5-AGGTGAAGCGAAGTGCACAC-3 (nt 1577-1596); the primers used for the inner round PCR system were 5-TTCCTGCTGGTGGCTCCAGTTC-3 (nt 54-75) and 5-TTCCGCAGTATGGATCGGCAG-3 (nt 1258-1278). PCR conditions were $94^{\circ} \mathrm{C}$ for $3 \mathrm{~min}$; 30 cycles of $94^{\circ} \mathrm{C}$ for $1 \mathrm{~min}, 60^{\circ} \mathrm{C}$ for $1 \mathrm{~min}$ and $72^{\circ} \mathrm{C}$ for $1.5 \mathrm{~min}$; then $72^{\circ} \mathrm{C}$ for $10 \mathrm{~min}$. The PCR products were purified using a QIAquick Gel Extraction Kit (Qiagen, Germany) and directly sequenced (Sangon Bioengineering, Shanghai, China). Nucleotide sequences were analyzed using DNAStar 5.0 and MEGA 4.0 software. Mutations of the HBV RT gene were determined by sequence alignment with the reference stains in GenBank. ${ }^{16}$

\section{Fibrosis staging}

Liver biopsies were obtained using a 17G core aspiration needle (Hepafix, Germany), with a biopsy length of $2 \sim 5 \mathrm{~cm}$. The biopsy specimens were fixed, paraffin-embedded, cut into 3 5 $\mu \mathrm{m}$ thick sections, and stained with haematoxylin and eosin (H\&E) and Masson's trichrome. The degree of liver fibrosis was evaluated by experienced hepato-pathologists, who were blinded to the clinical data of the patients. Staging of liver fibrosis was performed semi-quantitatively according to the published grading and staging system: F0, no fibrosis; F1, portal fibrosis without septa; F2, portal fibrosis and few septa; F3, numerous septa without cirrhosis; and F4, cirrhosis. ${ }^{17}$

\section{Statistical analysis}

Statistical analyses were performed using SPSS16.0 software (SPSS, Chicago, USA). The one-way ANOVA ttest or Pearson's $X^{2}$ test were used appropriately for continuous variables and categorical variables. The serum level of HBV DNA loads were expressed on a logarithmic scale. A p-value of less than 0.05 was considered to be statistically significant.

\section{Results}

\section{Patient characteristics}

The HBV RT gene was sequenced in all 288 treatmentnaïve chronic hepatitis $\mathrm{B}$ patients. The $\mathrm{HBeAg}$ positive rate was $71.18 \%(205 / 288)$, and all of them were genotype $\mathrm{B}$ or $\mathrm{C}$ with the HBV B/C ratio of $38.19 \% / 61.81 \%$ (110/178). Multiple comparisons of the main characteristics according to serum HBeAg positivity are shown in Table 1. HBeAg-negative patients were significantly older than the HBeAg-positive group, while no significant differences in gender, genotype, ALT, AST and TBIL were found between the HBeAg-positive and HBeAg-negative group.
Table 1. Characteristics of 288 treatment-naïve chronic hepatitis B patients

\begin{tabular}{|l|c|c|c|}
\hline \multicolumn{1}{|c|}{ Characteristics } & $\begin{array}{c}\mathrm{HBeAg}+\mathrm{CHB} \\
(\mathrm{N}=205)\end{array}$ & $\begin{array}{c}\mathrm{HBeAg}-\mathrm{CHB} \\
(\mathrm{N}=83)\end{array}$ & p-value \\
\hline Age (years) & $42.12 \pm 14.90$ & $46.56 \pm 13.61$ & 0.0169 \\
\hline $\begin{array}{l}\text { Gender } \\
\text { (male/female) }\end{array}$ & $131 / 74$ & $56 / 27$ & 0.5655 \\
\hline $\begin{array}{l}\text { Genotype } \\
\text { (type B/type C) }\end{array}$ & $79 / 126$ & $31 / 52$ & 0.8510 \\
\hline $\begin{array}{l}\text { HBV DNA } \\
\text { (log copies/mL) }\end{array}$ & $6.67 \pm 1.42$ & $5.49 \pm 1.33$ & $<0.0001$ \\
\hline ALT (U/L) & $353.41 \pm 376.74$ & $281.61 \pm 261.42$ & 0.1135 \\
\hline AST (U/L) & $74.76 \pm 102.23$ & $73.83 \pm 100.86$ & 0.9441 \\
\hline TBIL ( $\mu$ mol/L) & $169.44 \pm 159.85$ & $122.31 \pm 55.58$ & 0.0093 \\
\hline Platelet $\left(\times 10^{9} / \mathrm{L}\right)$ & & $504.30 \pm 546.09$ & 0.0984 \\
\hline
\end{tabular}

HBeAg - hepatitis B e antigen; HBV - hepatitis B virus;

ALT - alanine aminotransferase; TBIL - total bilirubin.

HBeAg-negative patients had much lower serum viral loads than $\mathrm{HBeAg}$-positive patients $\left(\mathrm{HBeAg}^{+}\right.$vs $\mathrm{HBeAg}$ : $10^{6.67}$ vs $10^{5.49}, \mathrm{p}<0.0001$ ), which is consistent with published data. ${ }^{18}$ Interestingly, HBeAg-negative patients also showed a significantly lower level of blood platelet than HBeAg-positive patients ( $\mathrm{p}=0.0093)$.

\section{Characterization of mutations in HBV RT gene from treatment-naiive CHB patients}

Among 288 treatment-naïve chronic hepatitis B patients, HBV RT mutations were found in a total of 71 patients (24.65\%). The distribution of amino acid mutant sites within the RT gene identified in this study is shown in Fig. 1. There was a total of 28 mutant sites, which formed 3 dominant mutant clusters: rt124-139, rt191-212 and rt225-229, indicating different susceptibility to mutations under a natural history of $\mathrm{HBV}$ replication. Although there were 3 patients that had mutations at the rt181 site (A181S), no well-defined primary nucleotide analog-resistant mutations (i.e. I169T, A181T/V, T184A/C/F/G/I/L/M/S, A194T,

Fig. 1. Amino acid substitutions at 28 positions of HBV reverse transcriptase analyzed in this study

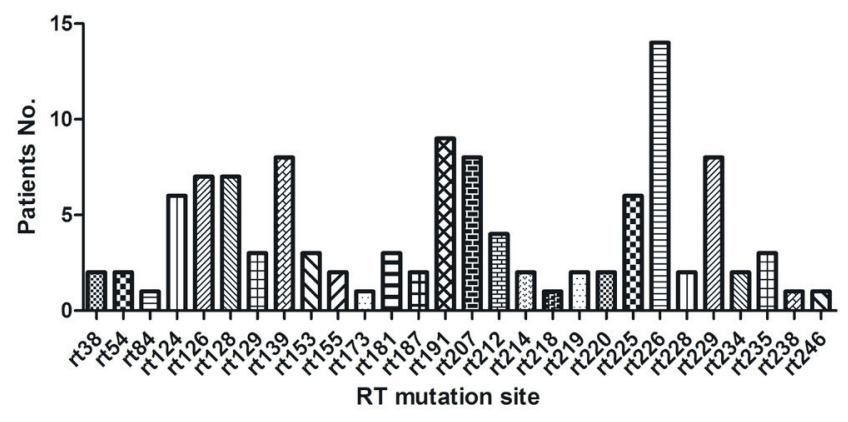


Fig. 2. Frequency of accumulation of amino acid substitutions in 71 patients with RT mutations

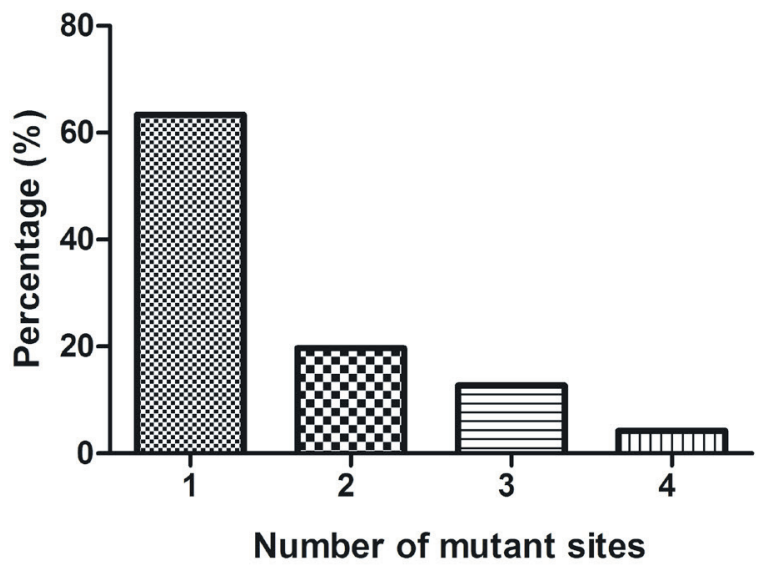

S202C/G/I, M204I/V/S, N236T, M250I/L/V) were found among these treatment-naïve patients. ${ }^{19,20}$ When analyzing the number of mutations in these 71 patients with a mutant RT gene, we found that $63.38 \%$ (45/71) patients had a single mutation while $19.72 \%$ (14/71), $12.68 \%(9 / 71)$ and $4.23 \%(3 / 71)$ of patients had 2,3 or 4 mutations, respectively (Fig. 2).

\section{Correlation between HBV RT mutations and clinical features}

To investigate the clinical significance of HBV RT mutations in treatment-naïve chronic hepatitis B patients, the clinical characteristics were compared between the 217 patients without RT mutations and the 71 patients with RT mutations. No significant differences were found in age, gender, HBV genotype, HBeAg status, ALT, AST and TBIL between patients with and without RT mutations (Table 2). However, patients with RT mutations showed significantly decreased serum baseline HBV DNA loads ( $\mathrm{p}=0.0363)$, indicating a much tougher environment for viral survival or replication. Furthermore, there was a much lower blood platelet count in patients with RT mutations ( $\mathrm{p}=0.0181$ ), demonstrating that there may be much deeper liver injury in these patients.

\section{Correlation between clinical features and number of RT mutations}

Among these 71 patients with RT mutations, 45 patients (63.38\%) had a single mutant site and 26 patients (36.62\%) had 2 or more mutant sites. A comparison of clinical characteristics between these 2 groups is summarized in Table 3. Although there were no significant differences in age, gender, HBV genotype, HBeAg status, ALT, AST and TBIL, the patients with multiple mutant sites $(\geq 2)$ had significantly decreased baseline HBV DNA loads ( $\mathrm{p}=0.0004$ ) and lower blood platelet count $(\mathrm{p}=0.0011)$, compared to patients
Table 2. Comparison of main characteristics of patients with and without HBV RT mutations

\begin{tabular}{|l|c|c|c|}
\hline \multicolumn{1}{|c|}{ Characteristics } & $\begin{array}{c}\text { Group with } \\
\text { mutations } \\
(\mathbf{n}=71)\end{array}$ & $\begin{array}{c}\text { Group without } \\
\text { mutations } \\
(\mathbf{n}=217)\end{array}$ & p-value \\
\hline Age (years) & $45.17 \pm 11.72$ & $42.83 \pm 14.91$ & 0.2289 \\
\hline $\begin{array}{l}\text { Gender } \\
\text { (male/female) }\end{array}$ & $48 / 23$ & $139 / 78$ & 0.5863 \\
\hline $\begin{array}{l}\text { Genotype } \\
\text { (type B/ type C) }\end{array}$ & $26 / 45$ & $84 / 133$ & 0.7531 \\
\hline $\begin{array}{l}\text { HBeAg } \\
\text { (positive/negative) }\end{array}$ & $5.02 \pm 1.28$ & $6.43 \pm 1.47$ & 0.0363 \\
\hline $\begin{array}{l}\text { HBV DNA } \\
(\text { Log copies/mL) }\end{array}$ & $561.36 \pm 613.59$ & $632.97 \pm 794.18$ & 0.4878 \\
\hline ALT (U/L) & $312.34 \pm 298.72$ & $339.38 \pm 382.13$ & 0.5868 \\
\hline AST (U/L) & $69.61 \pm 98.86$ & $76.09 \pm 104.07$ & 0.6452 \\
\hline TBIL ( $\mu$ mol/L) & $125.14 \pm 46.39$ & $165.91 \pm 141.87$ & 0.0181 \\
\hline Platelet (109/L) & 15493 \\
\hline
\end{tabular}

HBeAg - hepatitis B e antigen; HBV - hepatitis B virus; ALT - alanine aminotransferase; TBIL - total bilirubin.

with a single mutant site. It demonstrated that there may be much deeper injury in the liver of patients with multiple RT mutations and the liver environment of these patients was not good enough for viral survival or replication.

\section{Multiple RT mutations are associated with more severe liver fibrosis}

To investigate the relationship between RT mutations, especially multiple RT mutations, with liver disease se-

Table 3. Comparison of main characteristics of patients with different number of RT mutations

\begin{tabular}{|c|c|c|c|}
\hline Characteristics & $\begin{array}{c}\text { Single mutant } \\
\text { site } \\
(n=45)\end{array}$ & $\begin{array}{l}\text { Mutant sites } \\
\qquad \begin{array}{c}(\geq 2) \\
(n=26)\end{array}\end{array}$ & $p$-value \\
\hline Age (years) & $45.17 \pm 11.72$ & $42.83 \pm 14.91$ & 0.2289 \\
\hline $\begin{array}{l}\text { Gender } \\
\text { (male/female) }\end{array}$ & $48 / 23$ & 139/78 & 0.5863 \\
\hline $\begin{array}{l}\text { Genotype } \\
\text { (type B/ type C) }\end{array}$ & $26 / 45$ & $84 / 133$ & 0.7531 \\
\hline $\begin{array}{l}\text { HBeAg } \\
\text { (positive/negative) }\end{array}$ & $51 / 20$ & $154 / 63$ & 0.8891 \\
\hline $\begin{array}{l}\text { HBV DNA } \\
\text { (Log copies/mL) }\end{array}$ & $6.02 \pm 1.28$ & $6.43 \pm 1.47$ & 0.0363 \\
\hline $\mathrm{ALT}(\mathrm{U} / \mathrm{L})$ & $561.36 \pm 613.59$ & $632.97 \pm 794.18$ & 0.4878 \\
\hline AST (U/L) & $312.34 \pm 298.72$ & $339.38 \pm 382.13$ & 0.5868 \\
\hline TBIL ( $\mu \mathrm{mol} / \mathrm{L})$ & $69.61 \pm 98.86$ & $76.09 \pm 104.07$ & 0.6452 \\
\hline Platelet (109/L) & $125.14 \pm 46.39$ & $165.91 \pm 141.87$ & 0.0181 \\
\hline
\end{tabular}

HBeAg - hepatitis B e antigen; HBV - hepatitis B virus;

ALT - alanine aminotransferase; TBIL - total bilirubin. 
Fig. 3. Distribution of liver fibrosis in 164 treatment-naïve chronic hepatitis $B$ patients who had fibrosis staging performed based on the number of HBV RT mutations

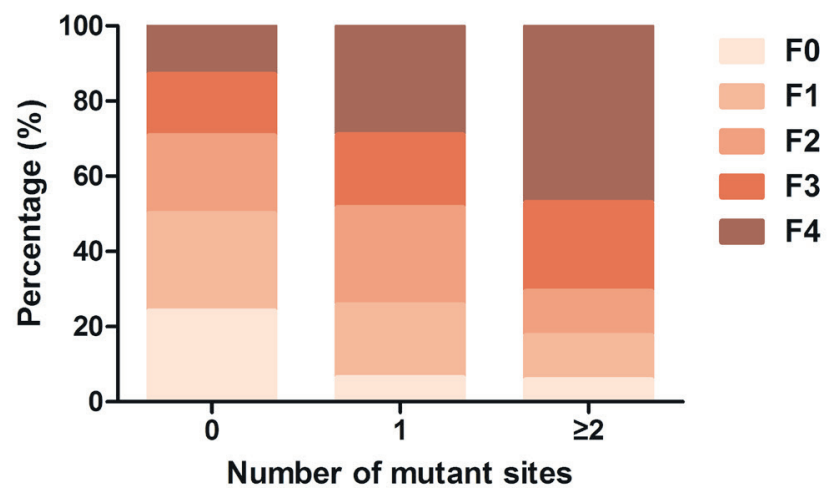

F0 - no fibrosis; F1 - portal fibrosis without septa; F2 - portal fibrosis and few septa; F3 - numerous septa without cirrhosis; F4 - cirrhosis.

verity in treatment-naïve chronic hepatitis B patients, a total of 164 individuals had liver biopsies performed: 116 patients without RT mutations, 31 patients with a single RT mutation, and 17 patients with multiple RT mutations. Liver fibrosis was evaluated semi-quantitatively: F0, no fibrosis; F1, portal fibrosis without septa; F2, portal fibrosis and few septa; F3, numerous septa without cirrhosis; and F4, cirrhosis. ${ }^{17}$ The distribution of liver fibrosis staging is showed in Fig. 3: the number of RT mutations is significantly associated with the severity of liver fibrosis ( $\mathrm{p}=0.0128) .24 .14 \%(28 / 116)$ of patients without RT mutations, $6.45 \%(2 / 31)$ of patients with a single RT mutation, and $5.88 \%(1 / 17)$ of patients with multiple RT mutations were diagnosed as F0 fibrosis (no fibrosis). $12.93 \%$ (15/116) of patients without RT mutations, $29.03 \%$ $(9 / 31)$ of patients with a single RT mutation, and $47.06 \%$ (8/17) of patients with multiple RT mutations had histological evidence of cirrhosis (F4 fibrosis).

\section{Discussion}

Reverse transcriptase (RT) preforms the major enzymatic activity for viral replication and the main target of antiHBV drugs such as nucleos(t)ide analogs (NAs). NAs are reverse transcriptase inhibitors which mimic the natural nucleosides and incorporate into the DNA chain so as to inhibit viral replication. ${ }^{21}$ Treatment of NAs is known as an effective way to restrain HBV replication and restore liver function. However, nucleoside analog-resistant mutations, which always occur at the RT region, are the biggest obstacle during NAs treatment. Moreover, nucleoside analog-resistant mutations were even found in treatmentnaïve chronic hepatitis B patients, so it is suggested that patients should be examined for RT mutations before NAs treatment. ${ }^{22}$ In this study, a total of 288 treatment- naïve chronic hepatitis patients were sequenced for the RT gene, and 71 patients $(24.65 \%)$ were found with mutations. Among these mutations, no well-characterized primary or secondary/compensatory nucleoside analog-resistant mutations (i.e. I169T, A181T/V, T184A/C/F/G/I/L/M/S, A194T, S202C/G/I, M204I/V/S, N236T, M250I/L/V) were found according to the classification summarized by previous reports. ${ }^{19,20}$ However, many mutations found in these treatment-naïve patients were putative nucleoside analogresistant mutations, which may potentially associate with NAs resistance or compensatory replication capacity. For instance, rtV191I, rtV207I and rtL229V have been reported resistant to lamivudine, and rtA181S, rtV214A and rtE218D have been shown potentially related to adefovir resistance. ${ }^{23-28}$ In any case, this data suggests that, rather than primary or secondary/compensatory nucleoside analog-resistant mutations, putative nucleoside analogresistant mutations showed high prevalence in untreated Chinese chronic hepatitis B patients. The biological and clinical significance of these putative nucleoside analogresistant mutations need to be further investigated.

The HBV RT gene consists of 6 functional domains ( $F, A, B, C, D$ and $E$ ) and 5 connecting interdomains (F-A, $\mathrm{A}-\mathrm{B}, \mathrm{B}-\mathrm{C}, \mathrm{C}-\mathrm{D}$ and $\mathrm{D}-\mathrm{E}){ }^{29}$ In this study, we found 28 mutant sites in treatment-naive patients, and these mutations didn't distribute evenly in the RT region. There were 3 dominant mutation clusters rt124-139, rt191-212 and rt225-229, located at the A-B interdomain, B-C interdomain/C domain and $\mathrm{C}-\mathrm{D}$ interdomain, respectively. These mutation hotspots showed much a higher frequency of mutations than other sites, indicating that interdomains in the RT region are more susceptible to mutation under natural interaction between HBV replication and host immune defense.

As HBV infection usually starts in early childhood and lasts for a lifetime, the possibility of these patients getting HBV infection from their relatives who ever received formal antiviral treatment is very small, because during their childhood, LMV, ADV, ETV, LdT and IFN treatment were not popular in China. (The first antiHBV drug LMV was approved by the FDA on 1998.) Since all the patients in this study were treatment-naïve and these RT mutations were selected under liver inflammation induced by the virus and host immune response, we compared the clinical data of patients with and without RT mutations and found that no significant differences were shown in age, gender, HBV genotype, HBeAg status, ALT, AST and TBIL. However, patients with RT mutations had significantly decreased serum baseline HBV DNA loads and much lower blood platelet. The decreased baseline HBV DNA loads reflected a tougher liver environment for viral survival and replication. Blood platelet count is an important index for liver fibrosis, and the much lower platelet count in patients with RT mutations indicated that there were fewer undamaged hepatocytes which can produce enough 
thrombopoietin or there was more severe hypersplenism resulting in platelet activation and depletion. ${ }^{30,31}$ In addition, decreased serum baseline HBV DNA loads and lower blood platelet were also found in patients with multiple mutant sites $(\geq 2)$, compared to patients with a single mutant site. Therefore, the significance of RT mutations in treatment-naïve chronic hepatitis B patients is a reflection of a much tougher liver environment for both virus and host.

Compared to serum markers of liver function such as ALT, AST, TBIL and blood platelet count or other noninvasive measures such as aspartate aminotransferase-toplatelet ratio index (APRI), liver biopsy is considered to be the gold standard to evaluate the severity of liver fibrosis. ${ }^{32,33}$ In this study, 164 chronic hepatitis B patients underwent liver biopsies before treatment. Liver fibrosis in patients with RT mutations was more severe than in patients without RT mutations, and liver fibrosis in patients with multiple mutant sites $(\geq 2)$ was more severe than in patients with a single mutant site. This is consistent with the result of a decreased blood platelet count in patients with RT mutations, because patients with liver fibrosis are always associated with dramatically decreased blood platelet count. ${ }^{34}$ The mechanistic explanation for the relationship between RT mutations and liver fibrosis is presently unclear. It could be speculated that the appearance of RT mutations was a sign of the interaction history between the HBV and host immune response in the liver environment. The appearance and accumulation of RT mutations reflected much longer or more severe liver inflammation, which plays a central role in the liver fibrosis of chronic hepatitis B patients. ${ }^{35}$ This was the overall effect of natural occurring RT mutations on untreated patients, and the biological or clinical significance of individual mutations (especially those dominant mutations) needs to be further explored.

Based on this data, we demonstrated that the appearance and accumulation of RT mutations in treatmentnaïve chronic hepatitis $B$ patients was associated with decreased baseline HBV DNA loads and blood platelet count as well as more severe liver fibrosis. These results reinforce the linkage between the viral mutation and clinical progression of chronic hepatitis, and emphasize that the natural accumulation of RT mutations is a process of viral survival and chronic liver fibrosis.

\section{References}

1. Lu FM, Zhuang H. Management of hepatitis B in China. Chin Med J (Engl). 2009;122:3-4.

2. Fattovich G, Bortolotti F, Donato F. Natural history of chronic hepatitis B: Special emphasis on disease progression and prognostic factors. J Hepatol. 2008;48:335-352.

3. Zhang X, Hou J, Lu M. Regulation of hepatitis B virus replication by epigenetic mechanisms and microRNAs. Front Genet. 2013;14:202.

4. Nowak MA, Bonhoeffer $S$, Hill AM, Boehme $R$, Thomas $H C$, McDade H. Viral dynamics in hepatitis B virus infection. Proc Natl Acad Sci U S A. 1996;93:4398-4402.
5. Vietheer PT, Netter HJ, Sozzi T, Bartholomeusz A. Failure of the lamivudine-resistant rtM204I hepatitis B virus mutants to efficiently support hepatitis delta virus secretion. J Virol. 2005;79:6570-6573.

6. Lei J, Wang $Y$, Wang LL, et al. Profile of hepatitis B virus resistance mutations against nucleoside/nucleotide analogue treatment in Chinese patients with chronic hepatitis B. Virol J. 2013;10:313.

7. Jardi R, Rodriguez-Frias F, Schaper M, et al. Hepatitis B virus polymerase variants associated with entecavir drug resistance in treatment-naive patients. J Viral Hepat. 2007;14:835-840.

8. Osiowy C, Villeneuve JP, Heathcote EJ, Giles E, Borlang J. Detection of $\mathrm{rtN} 236 \mathrm{~T}$ and $\mathrm{rtA181V/T}$ mutations associated with resistance to adefovir dipivoxil in samples from patients with chronic hepatitis $B$ virus infection by the INNO-LiPA HBV DR line probe assay. $J$ Clin Microbiol. 2006;44:1994-1997.

9. Wu Y, Gan Y, Gao F, et al. Novel natural mutations in the hepatitis B virus reverse transcriptase domain associated with hepatocellular carcinoma. PLoS One. 2014;9:e94864.

10. Torresi J. The virological and clinical significance of mutations in the overlapping envelope and polymerase genes of hepatitis B virus. J Clin Virol. 2002;25:97-106.

11. Tatsukawa M, Takaki A, Shiraha H, et al. Hepatitis B virus core promoter mutations G1613A and C1653T are significantly associated with hepatocellular carcinoma in genotype C HBV-infected patients. BMC Cancer. 2011;11:458.

12. Liu S, Zhang H, Gu C, et al. Associations between hepatitis B virus mutations and the risk of hepatocellular carcinoma: A meta-analysis. J Natl Cancer Inst. 2009;101:1066-1082.

13. Jang JW, Chun JY, Park YM, et al. Mutational complex genotype of the hepatitis $B$ virus $X$ /precore regions as a novel predictive marker for hepatocellular carcinoma. Cancer Sci. 2012;103:296-304.

14. Guideline on prevention and treatment of chronic hepatitis $B$ in China. Chin Med J (Engl). 2005;12:2159-2173.

15. Liu Y, Wang C, Zhong Y, et al. Genotypic resistance profile of hepatitis $B$ virus (HBV) in a large cohort of nucleos(t)ide analogue-experienced Chinese patients with chronic HBV infection. J Viral Hepat. 2011;18:e29-39.

16. Stuyver LJ, Locarnini SA, Lok A, et al. Nomenclature for antiviralresistant human hepatitis $B$ virus mutations in the polymerase region. Hepatology. 2001;33:751-757.

17. Batts KP, Ludwig J. Chronic hepatitis: An update on terminology and reporting. Am J Surg Pathol. 1995;19:1409-1417.

18. $\mathrm{Xu} \mathrm{J,} \mathrm{Wu} \mathrm{B,} \mathrm{Wang} \mathrm{JH,} \mathrm{et} \mathrm{al.} \mathrm{Pre-existing} \mathrm{mutations} \mathrm{in} \mathrm{reverse} \mathrm{tran-}$ scriptase of hepatitis B virus in treatment-naive chinese patients with chronic hepatitis B. PLoS One. 2015;10:e0117429.

19. Sayan M, Akhan SC, Senturk O. Frequency and mutation patterns of resistance in patients with chronic hepatitis B infection treated with nucleos(t)ide analogs in add-on and switch strategies. Hepat Mon. 2011;11:835-842.

20. Zoulim F, Locarnini S. Hepatitis B virus resistance to nucleos(t)ide analogues. Gastroenterology. 2009;137:1593-1608.

21. Song ZL, Cui YJ, Zheng WP, Teng DH, Zheng H. Diagnostic and therapeutic progress of multi-drug resistance with anti-HBV nucleos(t) ide analogues. World J Gastroenterol. 2012;18:7149-7157.

22. Singla B, Chakraborti A, Sharma BK, et al. Hepatitis B virus reverse transcriptase mutations in treatment Naïve chronic hepatitis $B$ patients. J Med Virol. 2013;85:1155-1162.

23. Wang $F$, Wang $H$, Shen $H$, Meng $C$, Weng $X$, Zhang W. Evolution of hepatitis $B$ virus polymerase mutations in a patient with $\mathrm{HBeAg}$ positive chronic hepatitis $B$ virus treated with sequential monotherapy and add-on nucleoside/nucleotide analogues. Clin Ther. 2009;31:360-366.

24. Ji D, Liu Y, Li L, et al. The rtL229 substitutions in the reverse transcriptase region of hepatitis B virus (HBV) polymerase are potentially associated with lamivudine resistance as a compensatory mutation. J Clin Virol. 2012;54:66-72.

25. Zöllner B, Sterneck M, Wursthorn K, et al. Prevalence, incidence, and clinical relevance of the reverse transcriptase V207I mutation outside the YMDD motif of the hepatitis B virus polymerase during lamivudine therapy. J Clin Microbiol. 2005;43:2503-2505.

26. Yang $H$, Westland $C E$, Delaney WE $4^{\text {th }}$, et al. Resistance surveillance in chronic hepatitis B patients treated with adefovir dipivoxil for up to 60 weeks. Hepatology. 2002;36:464-473. 
27. Liu Y, Li X, Xin S, et al. The rtA181S mutation of hepatitis B virus primarily confers resistance to adefovir dipivoxil. J Viral Hepat. 2015;22:328-334.

28. Ryu SH, Chung YH. Resistance to adefovir in patients with chronic hepatitis B. Korean J Hepatol. 2006;12:484-492.

29. Warner N, Locarnini S, Kuiper M, et al. The L80l substitution in the reverse transcriptase domain of the hepatitis B virus polymerase is associated with lamivudine resistance and enhanced viral replication in vitro. Antimicrob Agents Chemother. 2007;51:22852292.

30. Shoaei SD, Sali S, Karamipour M, Riahi E. Non-invasive histologic markers of liver disease in patients with chronic hepatitis B. Hepat Mon. 2014;14:e14228.

31. Wang X, Jiang W, Li F, et al. Abnormal platelet kinetics are detected before the occurrence of thrombocytopaenia in HBV-related liver disease. Liver Int. 2014;34:535-543.

32. Jin W, Lin Z, Xin Y, Jiang X, Dong Q, Xuan S. Diagnostic accuracy of the aspartate aminotransferase-to-platelet ratio index for the prediction of hepatitis B-related fibrosis: A leading meta-analysis. BMC Gastroenterol. 2012;12:14.

33. Singh S, Allen AM, Wang Z, Prokop LJ, Murad MH, Loomba R. Fibrosis progression in nonalcoholic fatty liver vs nonalcoholic steatohepatitis: A systematic review and meta-analysis of paired-biopsy studies. Clin Gastroenterol Hepatol. 2015;13:643-654.

34. Xianghong G, Guanping C, Fenghua Y, Jiayin W. Changes in platelet functional parameters and CD62 P expression in liver cirrhosis. Afr Health Sci. 2013:13:1079-1083.

35. Czaja AJ. Hepatic inflammation and progressive liver fibrosis in chronic liver disease. World J Gastroenterol. 2014;20:2515-2532. 